HYDROXYMETHYLANTHRAQUINONES FROM THE WASTES

\title{
FROM THE PRODUCTION OF RHAMNIL
}

\author{
A. V. Gotsiridze and É. P. Kemertelidze UDC 547.615.4:51/582.736
}

The rhamnil preparation suggested by the Institute of Pharmacochemistry of the Academy of Sciences of the Georgian SSR, which is isolated from the bark of the alder buckthorn, is widely used in medicine as a gentle laxative [1-3]. Rhamnil contains about $65 \%$ of hydroxymethylanthraquinones (HMA), consisting of frangulin (45\%), frangula emodin (12\%), and chrysophanol $(6 \%)$ [4].

The wastes from the production of rhamnil in the form of the ground raw material and the aqueous mother liquors still contain a considerable amount of active HMA. The ground material contains about $3.5 \%$ of HMA $(50 \%$ of their initial content of this material), and the aqueous mother liquor about $0.2 \%$.

In order to obtain the HMA, the ground material was treated with an aqueous solution of sodium hydroxide (pH 8.5-9). The extract was acidified with hydrochloric acid to $\mathrm{pH} \mathrm{3-4.} \mathrm{The} \mathrm{precipitate} \mathrm{was}$ dried and extracted with ethanol-chloroform $(1: 3)$. The ethanolic-chloroform extract deposited a yelloworange crystalline powder of combined HMAs having the same composition as the rhamnil preparation Yield 1\%.

The HMAs were extracted from the aqueous mother liquor with ethyl acetate, giving $0.18 \%$ of this material. It was separated on a column of silica gel. Elution was performed with chloroform and chloroform-ethanol. The ground material yielded four, and the mother liquor two, individual compounds, which were identified with authentic samples by their melting points, mixed melting points, elementary compositions, UV and IR spectra, and $\mathrm{R}_{f}$ values on paper and thin-layer chromatograms.

The substances isolated from the ground raw material for rhamnil were characterized as frangulin with $\mathrm{mp} 226-230^{\circ} \mathrm{C}$, frangula emodin with $\mathrm{mp} 260-262^{\circ} \mathrm{C}$, physcion with $\mathrm{mp} 206-208^{\circ} \mathrm{C}$, and chry sophanol with $\mathrm{mp} 201-203^{\circ} \mathrm{C}$, and the substances from the aqueous mother liquor were frangulin with $\mathrm{mp} 196-198^{\circ} \mathrm{C}$, and frangula emodin with $\mathrm{mp} 256-258^{\circ} \mathrm{C}$. The method for isolating the total HMAs has been introduced into the production of rhamnil in order to obtain an additional amount of this material.

\section{LITERATURE CITED}

1. E. P. Kemertelidze and V. Yu. Vachnadze, Tr. TNIKhFI, 9,5 (1960).

2. New Medicinal Substances [in Russian], Moscow (1963), p. 110.

3. A. V. Gotsiridze and É. P. Kemertelidze, Soobshch. Akad. Nauk Gruz SSR, 55, 2,317 (1969).

4. A. V. Gotsiridze and É. P. Kemertelidze, The Chemistry and Biologically Active Substances of Georgian Medicinal Plants [in Russian], Series 1, No. II (1969), pp. 255-260.

I. G. Kutateladze Institute of Pharmacochemistry, Academy of Sciences of the Georgian SSR. Translated from Khimiya Prirodnykh Soedinenii, No. 4, pp. 519-520, July-August, 1971. Original article submitted February 26, 1971.

- 1973 Consultants Bureau, a division of Plenum Publishing Corporation, 227 West 17th Street, New York, N. Y. 10011. All rights reserved. This article cannot be reproduced for any purpose whatsoever without permission of the publisher. A copy of this article is available from the publisher for $\$ 15.00$. 